\title{
Design of Interbody Fusion Cages of Ti6Al4V with Gradient Porosity Using a Selective Laser Melting Process for Spinal Fusion Arthroplasty
}

\author{
C. T. $\mathrm{Pan}^{* 1}$, C. H. Lin ${ }^{1}$, Y. S. Huang ${ }^{1}$, T. L. Yang ${ }^{1}$, S. Y. Chen², C. H. Ou ${ }^{1}$, L. Y. Chen², J. C. Huang ${ }^{2}$, J. S. C. Jang ${ }^{3}$, \\ H. K. $\operatorname{Lin}^{4}$, and D. Y. $\operatorname{Lin}^{5}$ \\ ${ }^{1}$ Department of Mechanical and Electro-Mechanical Engineering, National Sun Yat-Sen University, \\ Kaohsiung, 80424, Taiwan \\ ${ }^{2}$ Department of Materials and Optoelectronic Science, National Sun Yat-Sen University, Kaohsiung, \\ 80424, Taiwan \\ ${ }^{3}$ Department of Mechanical Engineering, National Central University, Chung-Li, 32001, Taiwan \\ ${ }^{4}$ Graduate Institute of Materials Engineering, National Pingtung University of Science and Tech- \\ nology, Pingtung, 91201, Taiwan \\ ${ }^{5}$ Industrial Technology Research Institute, Hsinchu, 31040, Taiwan \\ *E-mail: panct@mail.nsysu.edu.tw
}

\begin{abstract}
Interbody fusion cage surgery with discectomy has been the major surgical method for treating back pain and degenerative diseases. However, highly rigid fusion devices cause great concentrations of mechanical stress, engendering stress concentration effects. In this study, various geometric structures with single porosity and gradient porosity were designed and 3D printed with selective laser melting. ANSYS software was applied to analyze the stress and strain distributions for different motion modes. For a disc fusion cage comprising three concentric rings surrounding a solid cylinder, with gradient porosity values of $60 \%-70 \%-80 \%$-solid (from outside to inside), both the stress and strain showed closer agreement with the intervertebral disc stress and strain. Both the cage and the disc exhibited uniform stress distributions with bone, which would be able to avoid stress concentration. The patterns of the designed models were then printed using Ti-6Al-4V powders. The morphologies of the printed porous structures were examined by optical microscopy and scanning electron microscopy. The porosities of the printed specimens were investigated using the Archimedes method. The results revealed only minor geometric deviation between the computer-aided design patterns and the as-printed samples.
\end{abstract}

DOI: $10.2961 / \mathrm{jlmn} .2017 .01 .0007$

Keywords: cages, stress concentration, selective laser melting, 3D printing; gradient porosity, Ti$6 \mathrm{Al}-4 \mathrm{~V}$

\section{Introduction}

Traditionally, spinal fusion surgery has been a critical surgical method for treating degenerative diseases. There are numerous problems to be solved in terms of the accelerated degeneration of adjacent discs. This mainly occurs because a highly rigid implantation device induces considerable variations and concentration of mechanical stress, known as the stress concentration effect, causing long-term damage to vertebral bodies.

Most metal implants used in clinical practice are fully dense, without any porosity, but their elastic moduli are obviously higher than those of bone tissues. The loadings cannot be transferred efficiently from the metal implants to the adjacent bone tissue, leading to a stress shielding effect between implants and bones [1]. Consequently, the stresses are always absorbed by the implants, causing amyotrophy and osteonecrosis of bones around the implants, distortion of new bone, and reductions in the bearing capacities of connective parts [2]. With advancements in materials technology, various materials with high corrosion resistance and toughness, such as CoCrMo, CoNiCrMo, and Ti-6Al$4 \mathrm{~V}$, have been widely used for bone surgery and dental implant materials [3].

Titanium alloys are clinically employed for artificial bones and hard tissue implants in humans because they are light, nonmagnetic, weather resistant, and biocompatible, but they are difficult to form into complicated structures with porosity gradients [4]. Additive manufacturing (AM) methods have been attracting substantial interest for applications in free-form fabrication [4]; AM enables the direct fabrication of customized components that have free-form surfaces and cannot be easily manufactured by conventional processes [5, 6]. This versatility promotes the expansion of AM to medical fields, because individual patients always have idiosyncratic characteristics [7]. Selective laser melting (SLM) is one of the rapid manufacturing techniques in AM; SLM enables the direct manufacturing of threedimensional parts with high bulk density; the dimensions of these parts can reflect individual three-dimensional measurements [8]. In the field of biomaterials, especially in the context of implants, characteristics such as porosity and pore size are the most crucial factors for cell adhesion and 
proliferation $[9,10]$. The prospect of instantaneously generating tailored parts through SLM has aroused considerable interest in the fields of orthopedic and trauma surgery, where prostheses and implants must be individually shaped in numerous cases [8].

The compositions and biomechanical behaviors of vertebral bodies have been studied intensively to avoid and prevent vertebral damage [11-13]. After the first fusion surgery was reported in 1911, fusion surgery has been widely used to treat vertebral diseases such as degeneration after lumbar fusion [14, 15]. Various biomechanical studies relevant to clinical results have been conducted using finite element methods [16-22]. Li et al. reported that surface treatments, such as sand blasting, spraying, or sintering, could increase the roughness and surface area of implants [23]. An ideal scaffold provides cells with a structural framework so that these cells can proliferate and produce an extracellular matrix to form tissue [24]. Daculsi et al. showed that calcium phosphate ceramics (CaP ceramics) with a pore size range of $100-1000 \mu \mathrm{m}$ were efficient for bone ingrowth [25]. Spoerke et al. presented thin titanium struts, which may increase elastic and plastic deformation. From a mechanical viewpoint, the structure should be stiff enough but should not drastically exceed the stiffness of the real bone being replaced to avoid stress shielding [26].

Thus far, however, few studies have reported implants with gradient porosity. The AM technique may be suitable for fabricating bone implants with gradient porosity. Bone tissues can easily grow into an implant that has a gradient of pore sizes for adjacent pores; bone tissues can grow from the surface into the interior of the implant, strengthening the biological combination between bone tissues and the implant, and avoiding the stress concentration effect. Hence, in this study, various Ti-6Al-4V alloy devices, some with single porosity and others with gradient porosity, were fabricated using AM. First, 3D models were created using software; models of various types of bones were simulated with porosities varying from 35\% (outside) to $80 \%$ (inside). ANSYS software was used to analyze the stress and strain values of fusion cages with single and gradient porosities. Subsequently, Ti-6Al-4V powders were melted to 3D print fusion cages with either single or gradient porosities (single porosities of $40 \%, 50 \%, 60 \%, 70 \%$, and $80 \%$, and various gradient porosities) by SLM. The dimensions, morphologies, and mechanical properties of the as-printed samples were examined by optical microscopy (OM), compression testing, and scanning electrical microscopy (SEM). The porosity of the printed specimens was investigated the Archimedes method.

\section{Experimental and methods}

\subsection{Porous cage design}

In this study, the SolidWorks computer-aided design software program (SolidWorks, USA) was used to create cylindrical models with various porosities and having outside diameters of $10 \mathrm{~mm}$, pore sizes of 600 and $800 \mu \mathrm{m}$, and thicknesses of $2 \mathrm{~mm}$ (Fig. 1). However, for human implants, spongy structures with gradient porosity are essential to avoid the stress concentration effect. Therefore, three annular shapes with various porosities were developed for several cages. To obtain gradient porosity effects, the three annular shapes were integrated into one fusion cage. As shown in Fig. 2, the porosities from outside to inside were determined to be $60 \%, 70 \%$, and $80 \%$, with the outmost diameter of this model being $15 \mathrm{~mm}$, the second ring diameter being $11.25 \mathrm{~mm}$, the third ring diameter being $7.5 \mathrm{~mm}$, and the thickness being $10 \mathrm{~mm}$; the innermost part is a cylinder (which is either solid or has some other porosity).

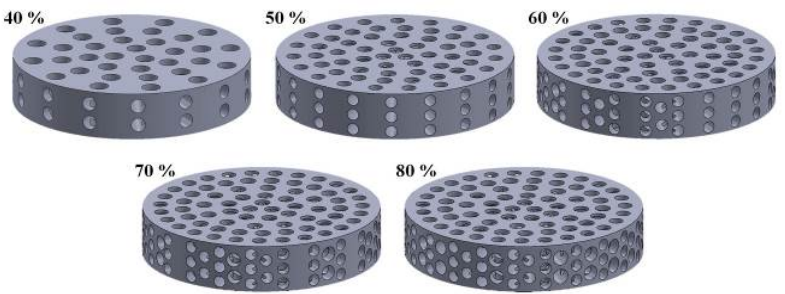

Fig. 1 Porosities of cylindrical fusion cages range from $40 \%$ to $80 \%$; models were coded in SolidWorks CAD software (SolidWorks, USA).

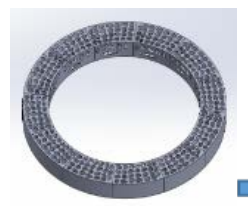

(a)

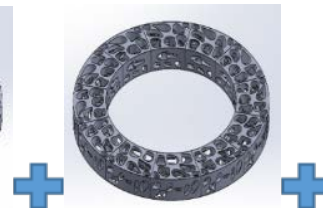

(b)

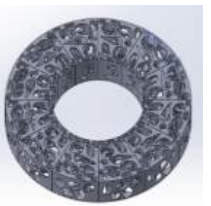

(c)

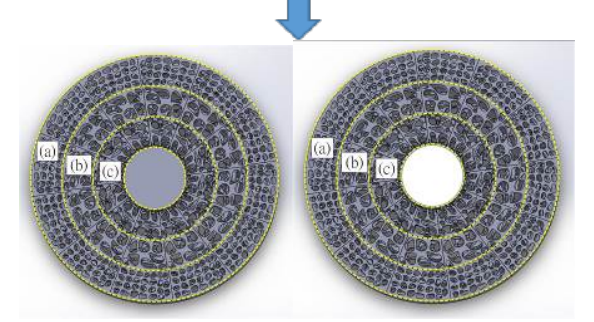

(d)

Fig. 2 Annular fusion cages with porosities of (a) 60\%, (b) $70 \%$, and (c) $80 \%$. (d) Gradient fusion cages with various porosities of $60 \%, 70 \%$, and $80 \%$ or other combinations.

\subsection{Porous elastic modulus calculation}

The elastic modulus and yield stress of a porous metal device typically depend on its porosity or relative density, as proposed by [27-29]. The deformation of the porous metal is assumed to be dominated by the bending of unit beams (or struts) under compression. The relationship between the elastic modulus and the relative density is given by,

$$
E / E_{s}=C_{1}\left(\rho / \rho_{s}\right)^{n_{1}}
$$

where $\mathrm{E}$ is the elastic modulus of the porous material, $E_{s}$ is the elastic modulus of the open-cell edge (wall) material, and $C_{1}$ and $n_{1}$ are constants that depend on the porous structure [30]. Normally, $n_{1}$ is a constant of approximately 2. The $C_{1}$ constants for porous structures depend on the bonding strengths of the cell ligaments, which mostly range from 0.1 to 4.0 .

For compression tests conducted to examine their mechanical properties, porous disc samples with diameters of 
$10 \mathrm{~mm}$ and thicknesses of $6 \mathrm{~mm}$ were prepared. The samples were tested at a strain rate of $1 \times 10^{-4} \mathrm{~s}^{-1}$ at room temperature by using an Instron 5582 universal testing machine, purchased from the United States, equipped with an Instron 2601 linear variable differential transformer displacement transducer. The experimental setup is shown in Fig. 3.

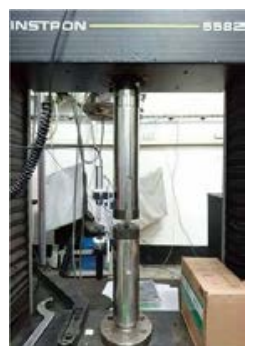

Fig. 3 Compression test setup of INSTRON 5582 system.

\subsection{Simulation}

In this study, the first priority was to establish a complete model of the vertebral joints, and to analyze the mechanical properties of the fusion cages of the vertebrae. This study was based on a basic two-sectional model of the L4-L5 vertebral joints. In addition, the parameters were set to the appropriate loading conditions of the stress and strain distributions of the spinal fusion cages and bones. A model of a section of spine with cartilage was created with information from computed tomography (CT), as shown in Fig. 4 (a). Fig. 4 (b) shows spinal bone models fused with a fusion cage with gradient porosity, Fig. 4 (c) shows a fusion cage with gradient porosity, and Fig. 4 (d) shows a cage with single porosity. External forces are assumed to be exerted on the models according to three different motion modes, namely a vertical body-weighted compression force of $400 \mathrm{~N}$, forward flexion moment of $7.5 \mathrm{Nm}$, and backward extension moment of $3.5 \mathrm{Nm}$ [31, 32]. The finite element model mesh had 1,400,984 elements and 2,192,553 nodes. The convergence requirement was set as less than $5 \%$. The three cases were analyzed and compared in terms of the stress and strain variations for devices subjected to these external loads.

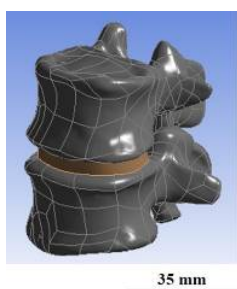

(a)

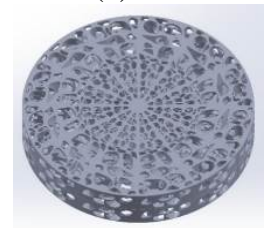

(c)

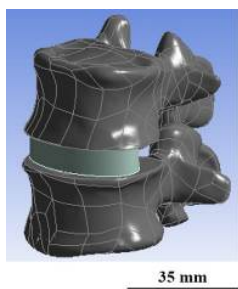

(b)

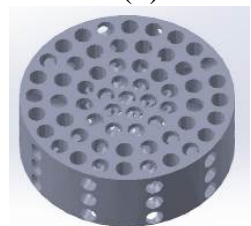

(d)
Fig. 4 Simulation 3D model: (a) vertebral CT of human bones, (b) vertebral CT of human bones implanted with fusion cages, (c) fusion cage with gradient porosity, and (d) fusion cage with single porosity.

\subsection{Additive manufacturing (SLM)}

SLM is a complex thermophysical process that involves numerous parameters. These parameters comprise laser parameters, including the laser power or laser spot diameter; scanning parameters; and material properties such as the surface tension and the thermal conductivity. The manufacturing process is characterized by highly localized high heat inputs during very short interaction times and therefore substantially affects the microstructure.

In this study, a fully automatic EOSINT M 280 was used to fabricate test samples directly from threedimensional CAD design data. It produces components by means of AM without any other tools. A fiber laser was used to melt the Ti-6Al-4V powder, and the product was built up layer by layer. This method can be applied to create products with gradient porosity. The $3 \mathrm{D}$ printing specimens were built under an Ar gas protective atmosphere, with a power of $190 \mathrm{~W}$, scanning speed of $1200 \mathrm{~mm} / \mathrm{s}$, beam diameter of $70 \mu \mathrm{m}$, and single layer thickness of 30 $\mu \mathrm{m}$. Open-cell porous sample models with different porosities and random micropore sizes ranging from 500 to 800 $\mu \mathrm{m}$ were made. The structures of the SLM-processed fusion cages were examined by SEM and OM.

\section{Results and discussion}

\subsection{Single-porosity fusion cage model}

Fig. 5 (a) shows the samples of various single-porosity fusion cages fabricated with SLM. The as-printed fusion cages show consistent geometric agreement with the design models, as shown in Fig. 5 (b). The results suggest that various fusion cage model designs can be printed using SLM.

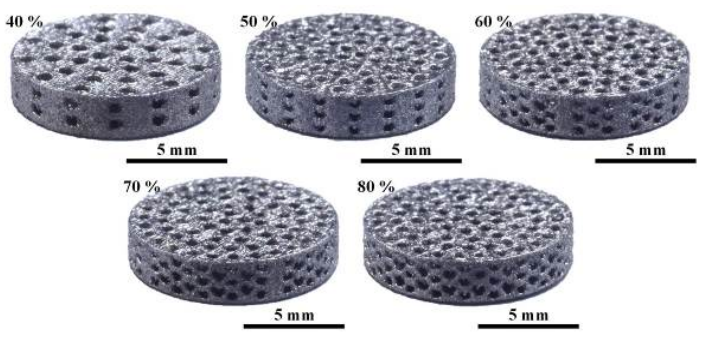

(a)

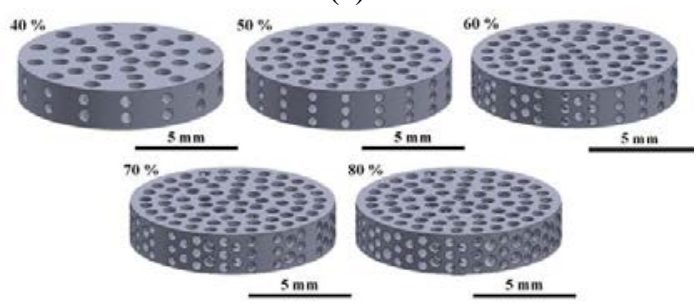

(b)

Fig. 5 Comparison of as-printed fusion cages and fusion cage models; (a) fabricated single-porosity fusion cages with porosities from $40 \%$ to $80 \%$; (b) 3D models of singleporosity fusion cages with porosities from $40 \%$ to $80 \%$.

The morphologies of the as-printed single-porosity fusion cages with porosities of $40 \%, 50 \%, 60 \%, 70 \%$, and $80 \%$ were measured by OM and SEM, and the results are 
presented in Figs. 6, 7, 8, 9, and 10, respectively. We compared the designed fusion cages and the as-printed ones, as shown in Figs. 6 (a) to 10 (a). The results showed that numerous partially melted powder particles accumulated in the pores and on the surfaces, causing the pores to become blocked and stuffed with the powder, even though an air gun was used to prevent powder accumulation. This occurred because the pores were so small that the air gun did not blow away the powder that accumulated during the printing process. Therefore, to some extent, enlarging the pores in the $3 \mathrm{D}$ models can effectively reduce this powder accumulation. The powders adhered around the pore walls, as shown in Figs. 6 (b) to 10 (b). The samples showed considerable amounts of partially melted powders around the pores; these partially melted powders caused some deviation from the designed geometries and dimensions, which increased the pore roughness levels and decreased the asprinted sample porosities. If these devices were implanted, the partially melted particles could be harmful to the patient because the particles might be released into the body.

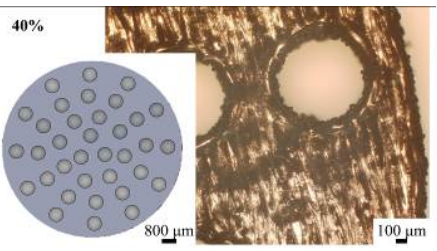

(a)

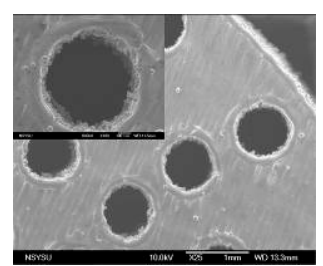

(b)
Fig. 6 Comparison between fusion cage model and asprinted fusion cage: (a) model with $40 \%$ porosity and a pore size of $800 \mu \mathrm{m}$ and an OM photograph of the asprinted fusion cage; (b) as-printed fusion cage with a pore size of $756 \mu \mathrm{m}$.

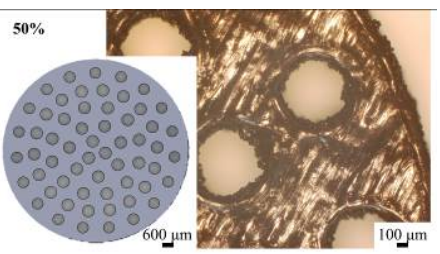

(a)

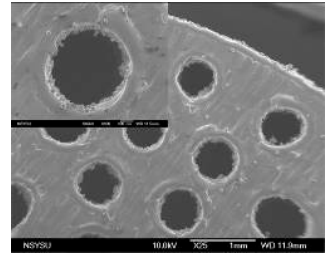

(b)
Fig. 7 Comparison between fusion cage model and asprinted fusion cage: (a) model with $50 \%$ porosity and a pore size was $600 \mu \mathrm{m}$ and an OM photograph of the asprinted fusion cage; (b) as-printed fusion with a pore size of $555 \mu \mathrm{m}$.

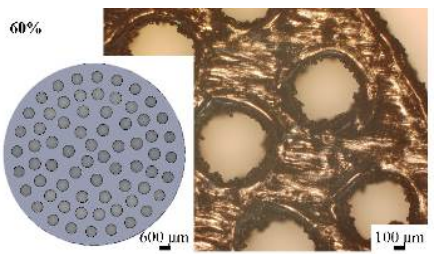

(a)

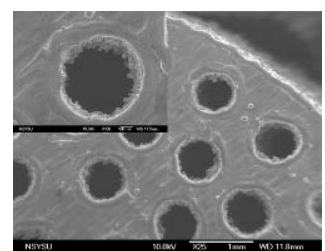

(b)
Fig. 8 Comparison between fusion cage model and asprinted fusion cage: (a) model with $60 \%$ porosity and a pore size of $600 \mu \mathrm{m}$ and an OM photograph of the asprinted fusion cage; (b) as-printed fusion cage with a pore size of $482 \mu \mathrm{m}$.

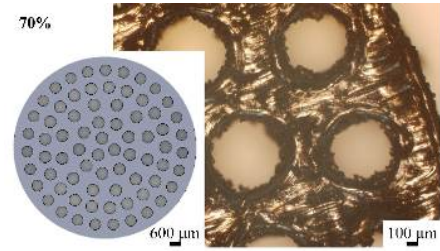

(a)

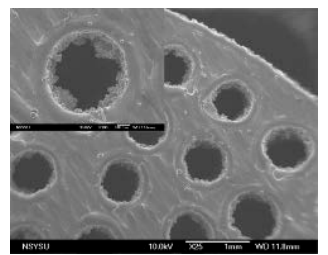

(b)
Fig. 9 Comparison between fusion cage model and asprinted fusion cage: (a) model with $70 \%$ porosity and a pore size of $600 \mu \mathrm{m}$ and an OM photograph of the asprinted fusion cage; (b) as-printed fusion cage with a pore size of $501 \mu \mathrm{m}$

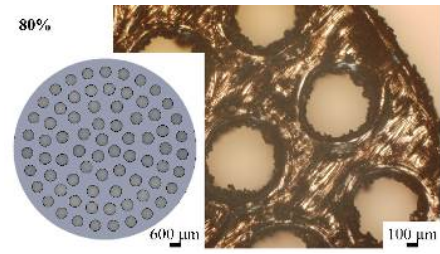

(a)

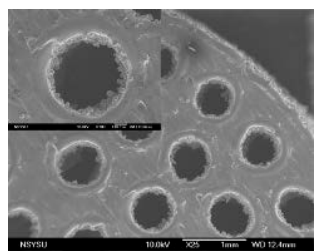

(b)
Fig. 10 Comparison between fusion cage model and asprinted fusion cage: (a) model with $80 \%$ porosity and a pore size of $600 \mu \mathrm{m}$ and an OM photograph of the asprinted fusion cage; (b) as-printed fusion cage with a pore size of $519 \mu \mathrm{m}$.

\subsection{Additive manufacturing and measurement of me- chanical properties}

\subsubsection{Measurement of porosities}

The SLM fusion cages were cleaned using supersonic vibration and then the porosities were measured; the results are shown in Fig. 11. The as-printed fusion cages that had been designed to have porosities of $40 \%, 50 \%, 60 \%, 70 \%$, and $80 \%$ were measured to have actual porosities of $39.51 \%$, 45.32\%, 52.57\%, 60.44\% and $60.05 \%$, respectively. Therefore, the fusion cages with higher porosities deviated obviously from the designs. This is because when the SLM process is printing a high-porosity fusion cage layer by layer, the rib between any two pores is small and tends to stack numerous partially melted particles, leading to porosity reduction.

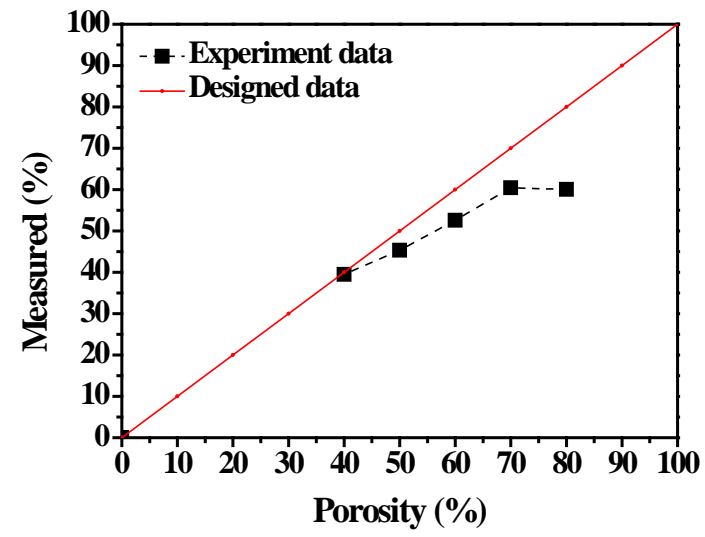

Fig. 11 Measured porosities of the as-printed samples designed to have porosities of $40 \%, 50 \%, 60 \%, 70 \%$, and $80 \%$. 


\subsubsection{Measurement of mechanical properties}

The Young's modulus values of the as-printed fusion cages with various porosities may be assumed to be proportional to their densities. The density of each porous fusion cage was measured from its weight and dimensions. The theoretical density of a solid mass of Ti-6Al-4V alloy is $4.37 \mathrm{~g} \mathrm{~cm}^{-3}$.

Three as-printed samples were tested as compression specimens on the Istron 5582 universal testing machine. Each sample had a diameter of $10 \mathrm{~mm}$ and a height of 6 $\mathrm{mm}$, with porosities of $40 \%, 60 \%$, and $80 \%$; the results are shown in Fig. 12. The elastic modulus values of porous samples decreased when the porosities increased, and the trend was nonlinear. The results agree with the Gibson and Ashby models [33].

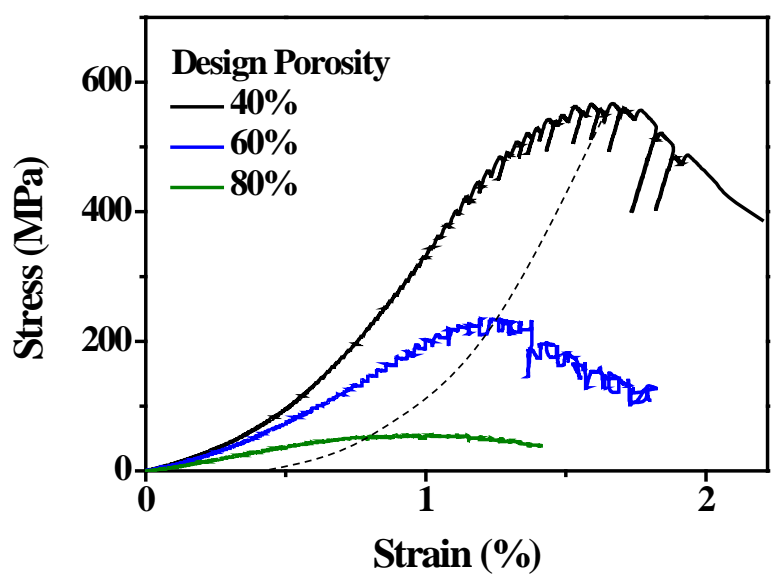

Fig. 12 Compression test results of the as-printed singleporosity samples with porosities of $40 \%, 60 \%$, and $80 \%$.

Therefore, according to Equation (1) and a paper from Wang et al. [34], $C_{1}$ and $n_{1}$ were set at 1.5 and 2, respectively. The Young's modulus as a function of porosity can be calculated and analyzed by fitting a regression curve. The density measurement data and modulus calculation results are shown in Figs. 13 (a) and 13 (b), revealing that the Young's modulus values decreased with the density and porosity. The material properties for the simulation are listed in Table 1.

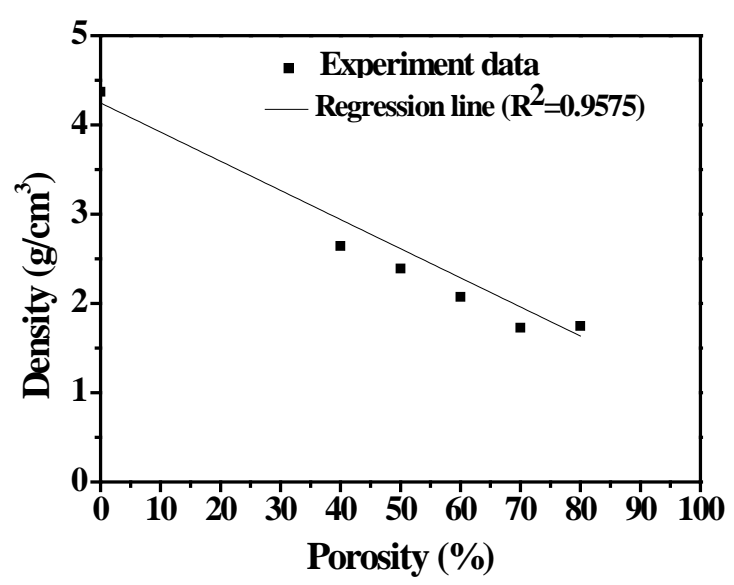

(a)

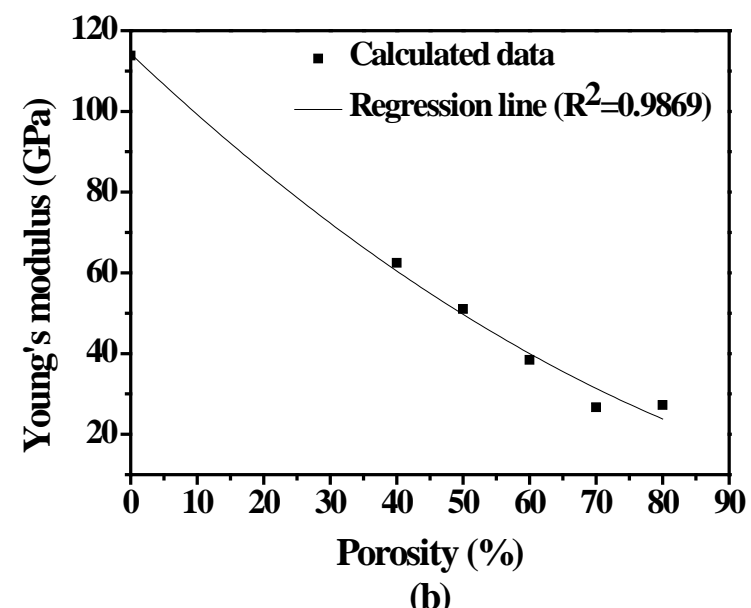

Fig. 13 (a) Density and (b) Young's modulus as a function of porosity.

Table 1 Material properties for simulation

\begin{tabular}{|c|c|c|c|c|}
\hline \multicolumn{2}{|l|}{ Material } & \multirow{2}{*}{$\begin{array}{r}\begin{array}{r}\text { Measured } \\
\text { density } \\
\left(\mathrm{g} / \mathrm{cm}^{3}\right)\end{array} \\
\\
4.37\end{array}$} & \multirow{2}{*}{$\begin{array}{c}\begin{array}{c}\text { Young's modulus } \\
(\mathrm{GPa})\end{array} \\
113.8\end{array}$} & \multirow{2}{*}{$\begin{array}{l}\text { Poisson's } \\
\text { ratio } \\
\\
0.3\end{array}$} \\
\hline \multirow{7}{*}{$\begin{array}{l}\text { porosity } \\
\text { of implant } \\
\text { fusion } \\
\text { cages }\end{array}$} & $0 \%$ & & & \\
\hline & $30 \%$ & 3.24 & 72.45 & 0.3 \\
\hline & $40 \%$ & 2.90 & 62.46 & 0.3 \\
\hline & $50 \%$ & 2.56 & 51.04 & 0.3 \\
\hline & $60 \%$ & 2.19 & 38.40 & 0.3 \\
\hline & $70 \%$ & 1.86 & 26.71 & 0.3 \\
\hline & $80 \%$ & 1.52 & 27.24 & 0.3 \\
\hline $\begin{array}{l}\text { Real cortica } \\
\text { [16] }\end{array}$ & bone & & 15 & 0.48 \\
\hline $\begin{array}{l}\text { Real spong. } \\
\text { [16] }\end{array}$ & bone & & 0.1 & 0.45 \\
\hline Real cartilag & [16] & & 2 & 0.4 \\
\hline
\end{tabular}




\subsection{Simulation results}

A spinal fusion cage surgery is designed to stop the motion of the painful vertebral segment. The upper and lower vertebrae can be fused to a fusion cage. If the implanted fusion cage can be secured to the vertebrae adjacent to it, then the structure is quite rigid and inflexible, which in turn decreases the pain generated from the joint. In the context of the biomechanics of single-porosity and gradientporosity spinal fusion cages, a finite element method was used to analyze the biomechanics of spinal fusion under three load modes, namely vertical compression, forward flexion, and backward extension.

In this finite element simulation, the lumbar region of a simulated spine was considered in various poses, including forward flexion, backward extension, and vertical compression. The simulation calculated the axial compressive load created by the weight of the upper body and the moment effects generated during forward flexion and backward extension. The loading modes of axial compression, forward flexion, and backward extension were simulated. For the three different motion modes, Fig. 14 shows the simulated conditions of vertebral bodies implanted with various fusion cages and without fusion cages when subjected to a vertical compression force of $400 \mathrm{~N}$, forward flexion moment of $7.5 \mathrm{Nm}$, and backward extension moment of $3.5 \mathrm{Nm}$. The boundary conditions were set at the L4 and L5 joints, and were completely fixed. The displacements along vertebral bodies were observed.

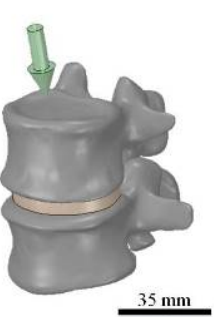

(a)

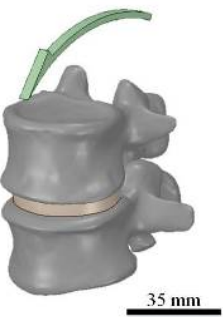

(b)

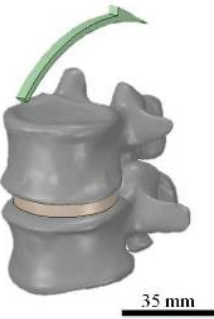

(c)
Fig. 14 Three external loads exerted on different motion modes.

In this simulation, the load was serially applied by the upper vertebra on the interbody fusion cage and by the interbody fusion cage on the bottom vertebra. Fusion cages for spinal fusion surgery should not produce any stressshielding effect. However, if moment forces (forward and backward) are loaded on the vertebrae and intervertebral discs, a mismatch between the fusion cage and the vertebra elastic modulus can engender a nonuniform stress distribution and stress concentration. The bones and fusion discs were cross-sectioned for clearer observation of their stress and strain behaviors. When the porosity distribution of a fusion cage (i.e., its elastic modulus) matches those of the upper and lower vertebrae, the induced stress and strain on the fusion cage can be reduced. Fig. 15 shows the distributions of the Von Mises stress and strain. When the cage porosity was uniformly $80 \%$, the stress distribution was superior to those of the other porous cages, but the strain effect was increased. When the gradient porosity of the cage, from inside to outside, was $60 \%-70 \%-80 \%$-solid, the stress distribution was similar to that of the single-porosity cage with $80 \%$ porosity, and the strain of the gradientporosity cage was lower than that of the $80 \%$ porosity cage. Clearly, the trends of the gradient fusion cages, particularly the maximum stress and strain distributions for the three motion modes, show high agreement with the trends of the simulated intervertebral discs. This demonstrates that the gradient fusion cages exhibit potential applications to future fusion implants. The authors designed devices with high-porosity outer rings to demonstrate the ability to design such devices. In this study, inside and outside rings with high gradients were designed.

\begin{tabular}{|c|c|c|c|}
\hline $\begin{array}{c}\text { Simula- } \\
\text { tion re- } \\
\text { sults }\end{array}$ & $\begin{array}{c}\text { Vertical } \\
\text { compression }\end{array}$ & $\begin{array}{c}\text { Forward } \\
\text { flexion }\end{array}$ & $\begin{array}{l}\text { Backward } \\
\text { extension }\end{array}$ \\
\hline $\begin{array}{c}\text { Interver- } \\
\text { tebral } \\
\text { disc }\end{array}$ & & & \\
\hline $\begin{array}{l}\text { Solid } \\
\text { fusion } \\
\text { cages }\end{array}$ & & & \\
\hline $\begin{array}{c}\text { Single } \\
30 \% \\
\text { porosity } \\
\text { of fusion } \\
\text { cage }\end{array}$ & & & \\
\hline $\begin{array}{c}\text { Single } \\
40 \% \\
\text { porosity } \\
\text { of fusion } \\
\text { cage }\end{array}$ & & & \\
\hline $\begin{array}{c}\text { Single } \\
50 \% \\
\text { porosity } \\
\text { of fusion } \\
\text { cage }\end{array}$ & & & \\
\hline $\begin{array}{c}\text { Single } \\
60 \% \\
\text { porosity } \\
\text { of fusion } \\
\text { cage }\end{array}$ & & & \\
\hline $\begin{array}{c}\text { Single } \\
70 \% \\
\text { porosity } \\
\text { of fusion } \\
\text { cage }\end{array}$ & & & \\
\hline $\begin{array}{c}\text { Single } \\
80 \% \\
\text { porosity } \\
\text { of fusion } \\
\text { cage }\end{array}$ & & & \\
\hline $\begin{array}{l}\text { The gra- } \\
\text { dient } \\
\text { porosity } \\
\text { distribu- } \\
\text { tion : }\end{array}$ & & & \\
\hline
\end{tabular}



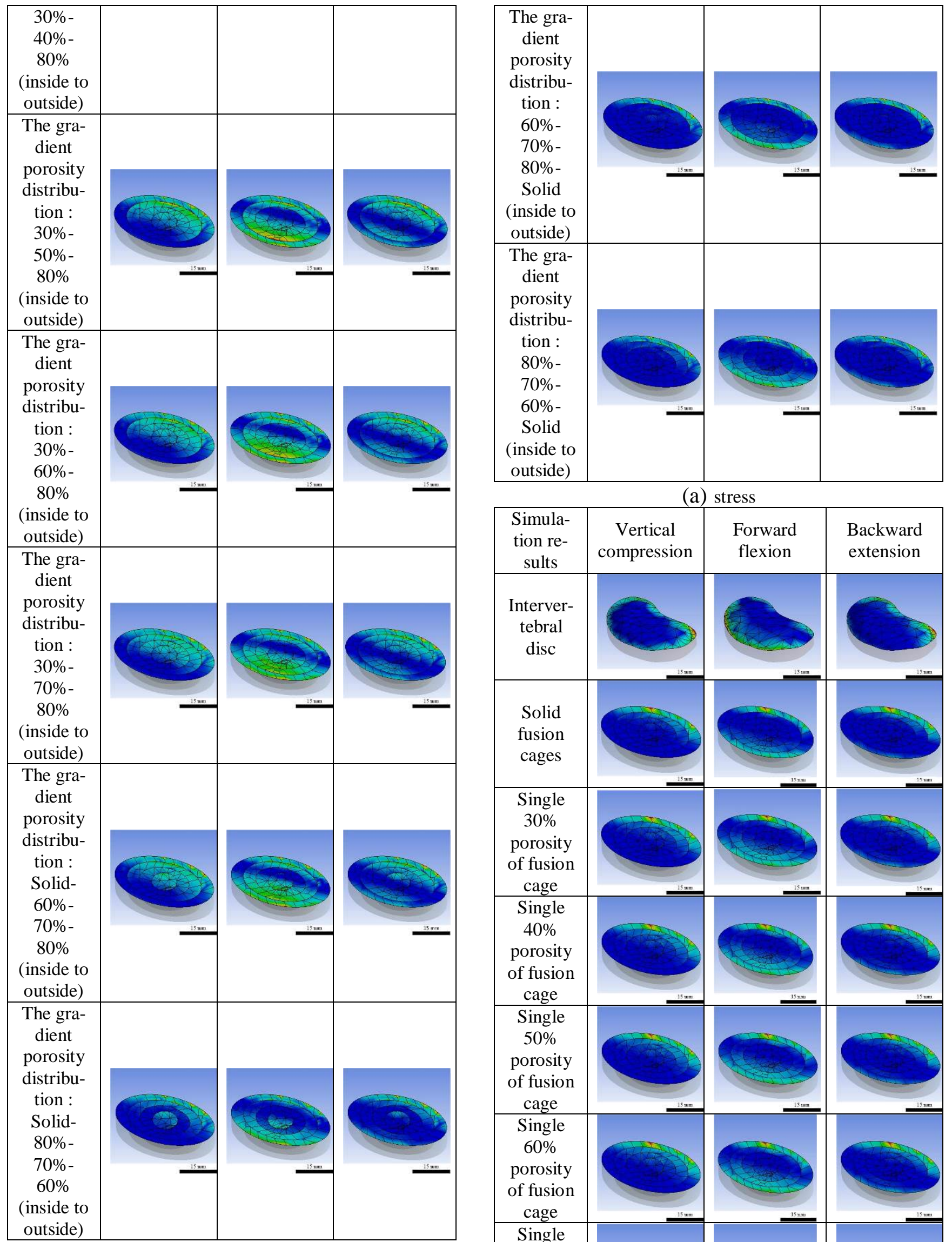

\begin{tabular}{|c|c|c|c|}
\hline \multicolumn{4}{|c|}{ (a) stress } \\
\hline $\begin{array}{l}\text { Simula- } \\
\text { tion re- } \\
\text { sults }\end{array}$ & $\begin{array}{c}\text { Vertical } \\
\text { compression }\end{array}$ & $\begin{array}{l}\text { Forward } \\
\text { flexion }\end{array}$ & $\begin{array}{l}\text { Backward } \\
\text { extension }\end{array}$ \\
\hline $\begin{array}{c}\text { Interver- } \\
\text { tebral } \\
\text { disc }\end{array}$ & & & \\
\hline $\begin{array}{l}\text { Solid } \\
\text { fusion } \\
\text { cages }\end{array}$ & & & \\
\hline $\begin{array}{c}\text { Single } \\
30 \% \\
\text { porosity } \\
\text { of fusion } \\
\text { cage }\end{array}$ & & & \\
\hline $\begin{array}{c}\text { Single } \\
40 \% \\
\text { porosity } \\
\text { of fusion } \\
\text { cage }\end{array}$ & & & \\
\hline $\begin{array}{c}\text { Single } \\
50 \% \\
\text { porosity } \\
\text { of fusion } \\
\text { cage }\end{array}$ & & & \\
\hline $\begin{array}{c}\text { Single } \\
60 \% \\
\text { porosity } \\
\text { of fusion } \\
\text { cage }\end{array}$ & & & \\
\hline $\begin{array}{c}\text { Single } \\
70 \% \\
\text { porosity } \\
\text { of fusion } \\
\text { cage }\end{array}$ & & & \\
\hline
\end{tabular}




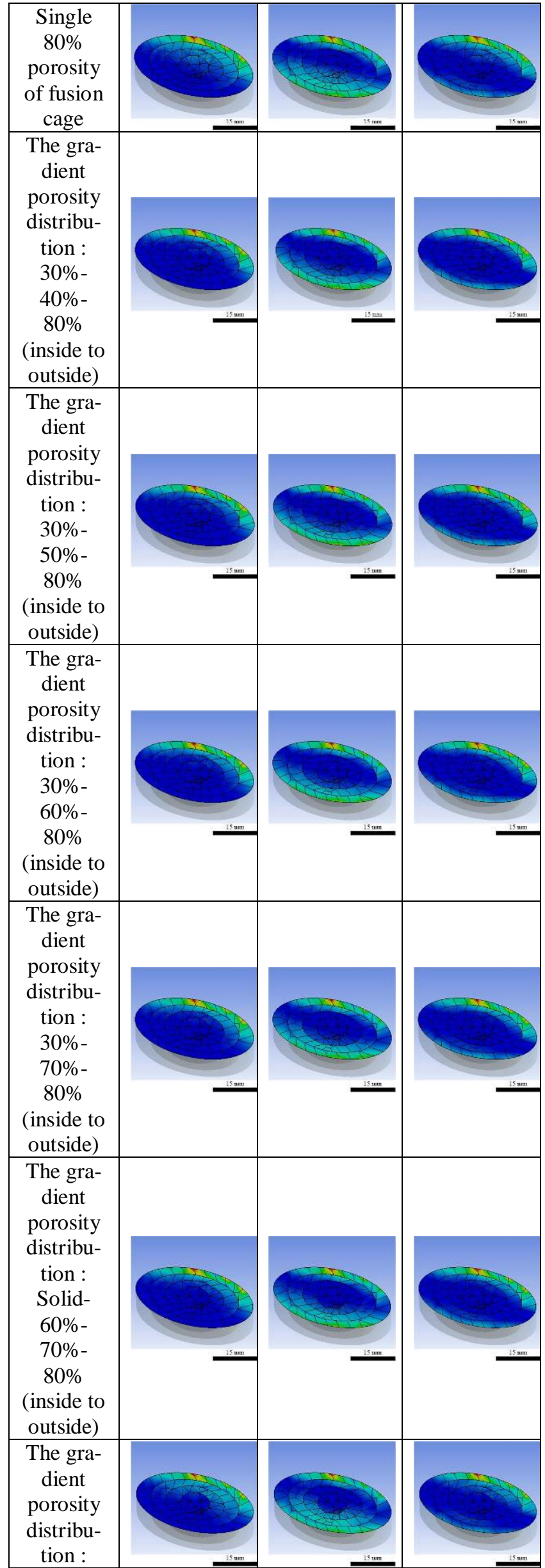

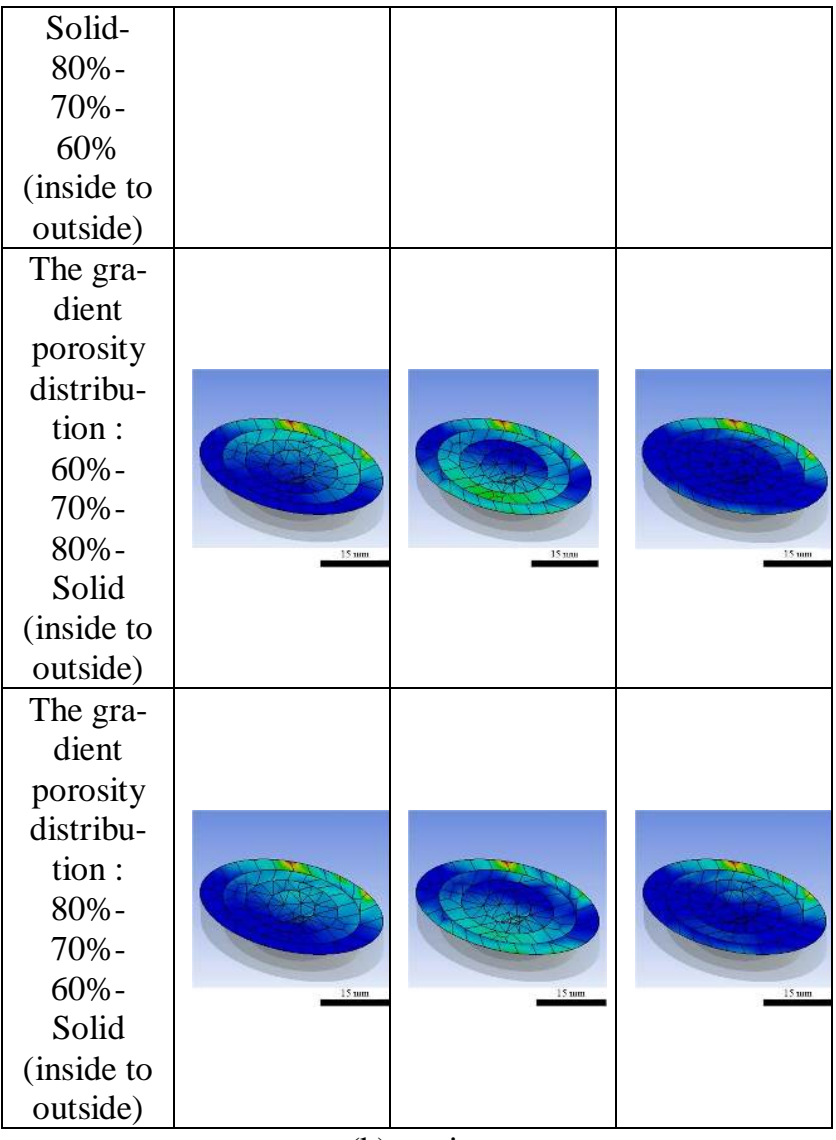

(b) strain

Fig. 15 Distribution of the maximum Von Mises (a) stress and (b) strain.

To evaluate the stress and strain quantitatively, the stress and strain as functions of fusion cages with various porosities were analyzed and determined for the three different motion modes, as shown in Figs. 16 and 17. The stress distributions in the intervertebral disc for the three motion modes were 4.49, 8.76, and 4.09 MPa. The optimal stress distributions in the intervertebral discs with gradient porosity were $3.85,5.18$, and $7.74 \mathrm{MPa}$. The simulated results were compared with those of the intervertebral disc. For all single-porosity fusion cages, the stress values were proportional to the Young's modulus, but the strain values were inversely proportional to the Young's modulus. Although the single-porosity devices exhibited lower stress, they had higher strain, leading to lower reliability. These results suggest that fusion cages should be fabricated with gradient porosity for long-term implantation; these devices can trade off the dilemma between stress and strain to avoid the risk of bone fracture over long periods. The simulated results reveal that both the stress and strain behaviors of the fusion cages with gradient porosity showed closer agreement with the intervertebral disc, as demonstrated by the $60 \%-70 \%-80 \%$-solid device shown in Figs. 16 (a) to 16 (c) and Figs. 17 (a) to 17 (c). This indicates that fusion cages could be optimized in terms of stress and strain and could be customized for each patient's individual needs and personal bone structure. 

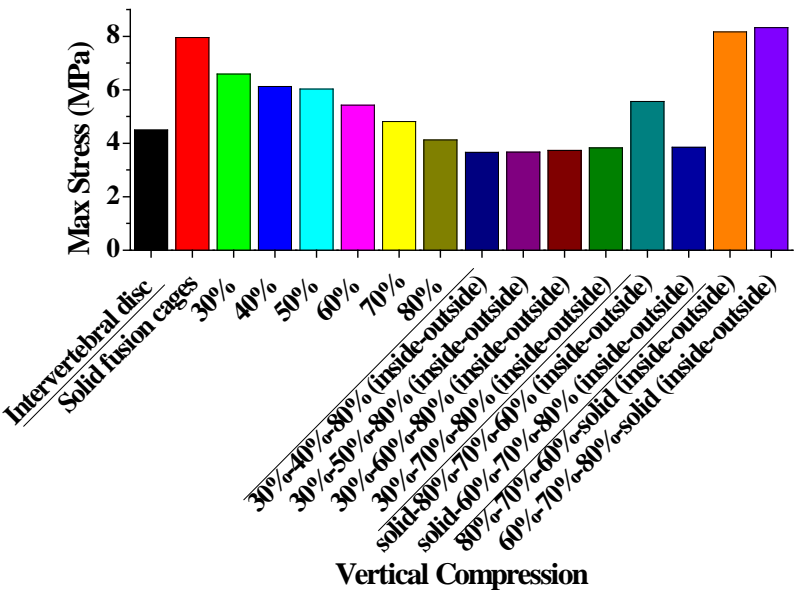

(a)
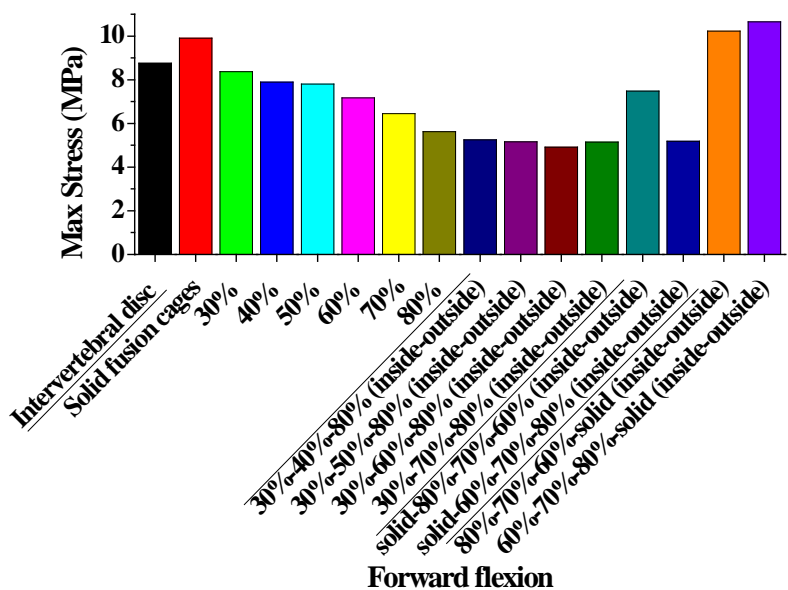

(b)
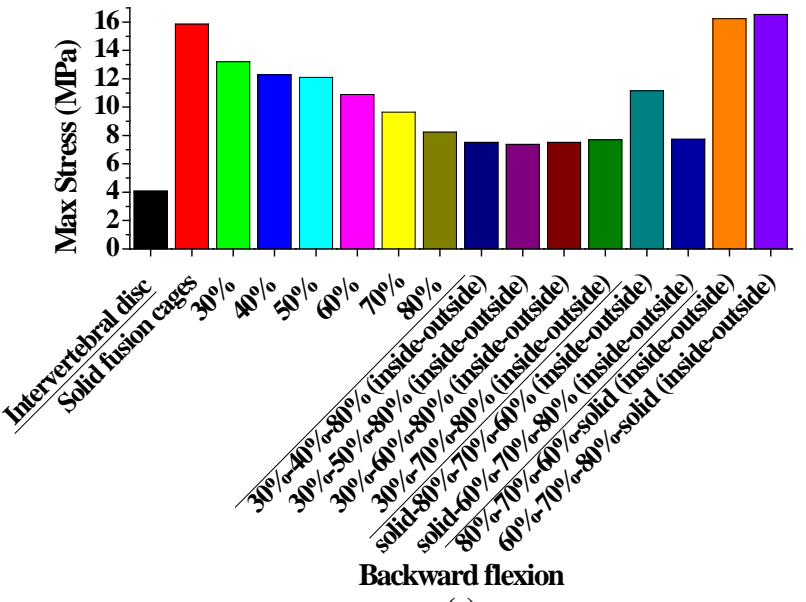

(c)

Fig. 16 Stress as a function of fusion cages with various porosities for three different motion modes: (a) vertical compression, (b) forward flexion, and (c) backward flexion.
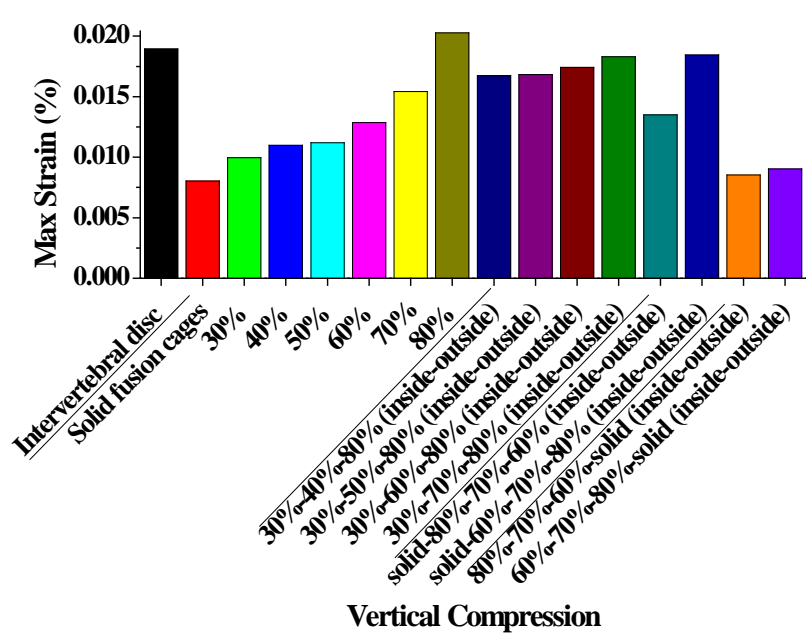

(a)

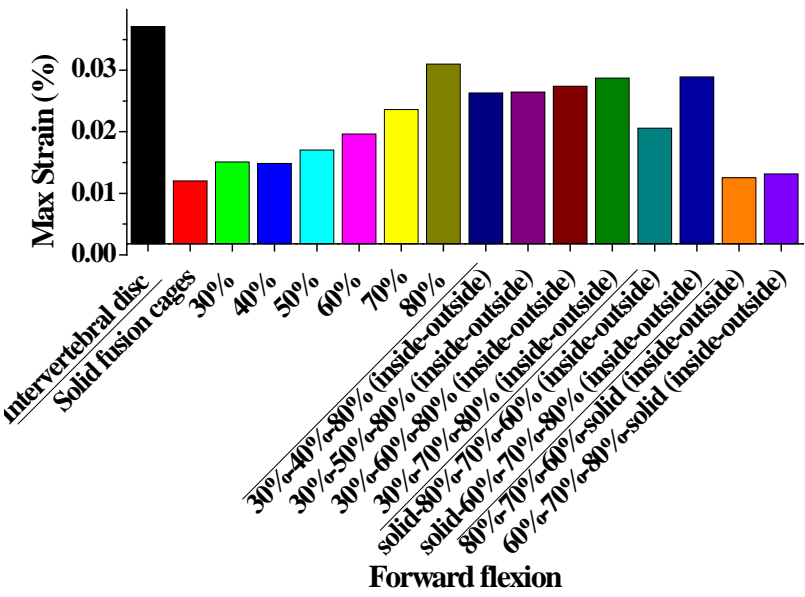

(b)
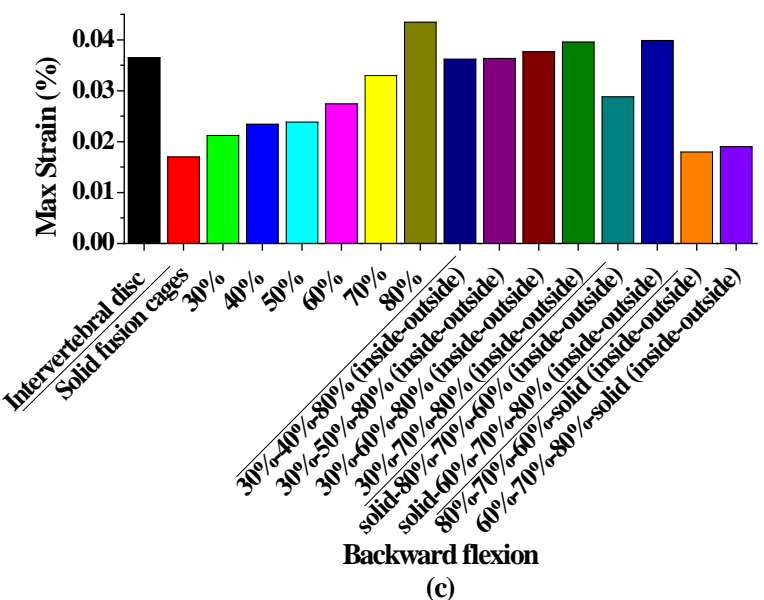

Fig. 17 Strain as a function of fusion cages with various porosities for three different motion modes: (a) vertical compression, (b) forward flexion, and (c) backward flexion.

\subsection{Gradient-porosity bone printing for SLM}

On the basis of the experimental and simulated results of the single-porosity devices, gradient-porosity fusion cages were designed. The gradient-porosity fusion cage models are shown in Fig. 18. Fig. 18 (a) shows the asprinted gradient-porosity fusion cage devices. The as- 
printed fusion cages showed geometric agreement with the design models, as shown in Fig. 18 (b). The surfaces showed no obvious powders left behind. The outside porosity was $80 \%$, and then the porosity varied from outside to inside (the inmost cylinders were solid).
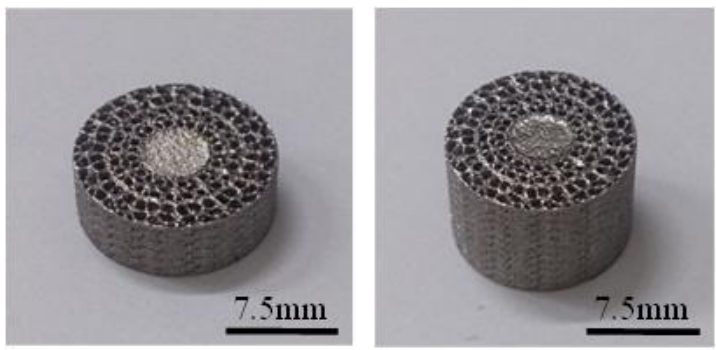

(a)
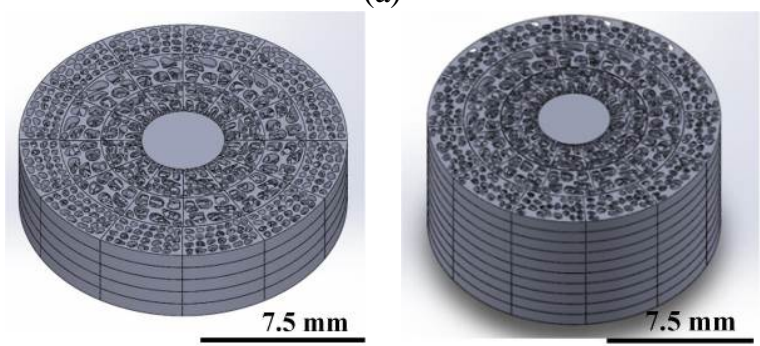

(b)

Fig. 18 (a) Gradient fusion cage sections from outside to inside were $80 \%, 70 \%, 60 \%$, and solid; (b) gradientporosity models.

Compared with the single-porosity devices, the pores of the gradient-porosity devices were relatively large; thus, the microball powders were successfully blown away and did not pile up around the pores. The pores and internal structures were clearly visible, as shown in Figs. 19 (a) to 19 (c).

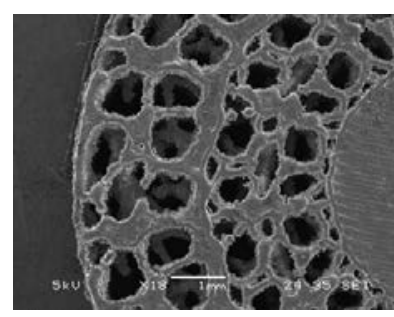

(a)

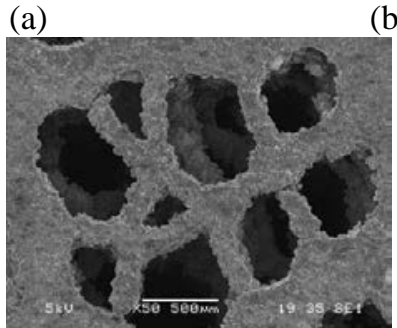

(c)

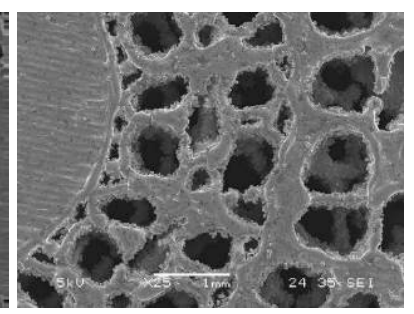

(b)
Fig. 19 SEM pictures of gradient disc devices with porosities of (a) $80 \%$, (b) $70 \%$, and (c) $60 \%$.

\section{Conclusions}

Various fusion cages were designed using SolidWorks software and then fabricated by SLM. Various porosities from $30 \%$ to $80 \%$ were developed. The pore sizes of the designed models showed similar trends to those of the SLM samples. A comparison of the SolidWorks fusion cage models and as-printed SLM devices showed that the geometrical and dimensional deviations were higher when the designed pores were small. The partially melted powders around the pores may have been responsible for this deviation. The single-porosity fusion cages (such as the $80 \%$ cage) exhibited lower stress, but higher strain, leading to lower reliability. The gradient-porosity devices with the 60\%-70\%-80\%-solid design showed a stress distribution similar to the $80 \%$ porosity cage, but the gradient-porosity devices had lower strain than the $80 \%$ porosity cage. Thus, the gradient-porosity devices avoided stress concentration. This suggests that gradient-porosity cages might avoid the risk of bone fracture even if they were implanted for long periods. The result also suggests that fusion cages could be optimized in terms of stress and strain and could be customized for the personal needs and distinct bone structures of individual patients.

\section{Acknowledgments}

The authors gratefully acknowledge the sponsorship of the Ministry of Science and Technology of Taiwan, ROC, under the project No. MOST 103-2218-E-110-011 and 3D printing support from the Industrial Technology Research Institute.

\section{References}

[1] Zhou Linxi, Yang Quanzhan, Zhang Guirong, et al.: China Foundry, 11, (2014) 322.

[2] Hu Haibo, Liu Huiqun, Wang Jieen, Yi Danqing, Fu Shang, and Sun Wuling: Materials Review, 26, (2012) 262.

[3] H. Hermawan, D. Ramdan, and J. R. P. Djuansjah: "Biomedical Engineering" ed. (publisher, InTech, 2011) p.411.

[4] Y. Sato, M. Tsukamoto, Y. Yamashita: Applied Physics B-Lasers and Optics, 119, (2015) 545.

[5] X. B. Su, Y. Q. Yang, P. Yu, and J. F. Sun: Transactions of Nonferrous Metals Society of China, 22, (2012) s181.

[6] H. Schleifenbaum, W. Meiners, K. Wissenbach, and C. Hinke: CIRP Journal of Manufacturing Science and Technology, 2, (2010) 161.

[7] J. Giannatsis, V. Dedoussis: International Journal of Advanced Manufacturing Technology, 40, (2009) 116.

[8] S. Hoeges, M. Lindner, H. Fischer, W. Meiners, and K. Wissenbach: Proc. 4th European Conference of the International Federation for Medical and Biological Engineering. (2009) p.2230.

[9] D. J. Botsford, S. I. Esses, and D. J. Ogilvie-Harris: Spine (Phila Pa 1976), 19, (1994) 935.

[10]K. B. Broberg: Journal of Biomechanics, 26, (1993) 501.

[11]M. N. DirSci and V. H. Frankel:"Basic biomechanics of the musculoskeletal system” 4 ed. (Publisher, Lippincott Willians and Wilkins, 2012) p.66

[12] S. Freudiger, G. Dubois, and M. Lorrain: Archives of Orthopaedic and Trauma Surgery, 119, (1999) 127.

[13] T. M. Stoll, G. Dubois, and O. Schwarzenbach: Eur Spine J., 11, (2002) S170.

[14]E. R., H. G. A., and S. B. C. A. J.: Proc. 5th world congress on computational mechanics., Vienna, (2002) p.1 
[15] D. S. Shin, K. Lee, and D. Kim: Computer-Aided Design, 39, (2007) 559.

[16] A. Reyes-Sanchez, B. Zarate-Kalfopulos, I. RamirezMora, L. M. Rosales-Olivarez, A. Alpizar-Aguirre, and G. Sanchez-Bringas: Eur Spine J, 19, (2010) 2164.

[17] I. Yamamoto, M. M. Panjabi, T. Crisco, and T. Oxland: Spine (Phila Pa 1976), 14, (1989) 1256.

[18]H. Kyogoku, Y. Shimizu, and K. Yoshikawa: Proc. Solid freeform fabrication symposium, Austin, Texas, (2013) p.846.

[19] V. Karageorgiou and D. Kaplan: Biomaterials, 26, (2005) 5474.

[20] N. Tajima, E. Chosa, K. Totoribe, S. Kubo, and H. Kuroki: Journal of Musculoskeletal Research, 02, (1998) 101.

[21] K. Totoribe, N. Tajima, and E. Chosa: Journal of Orthopaedic Science, 4, (1999) 115.

[22] A. Rohlmann, T. Zander, and G. Bergmann: Spine (Phila Pa 1976) , 30, (2005) 738

[23] Q. Li, H. Wang, LX. Zhang: Chinese Journal of Medical Instrumentation, 26:1, (2002) 44.

[24] C. M. Agrawal: Jom, 50, (1998) 31.

[25] G. Daculsi and N. Passuti: Biomaterials, 11, (1990) 86.

[26] E. D. Spoerke, N. G. Murray, H. Li, L. C. Brinson, D. C. Dunand, and S. I. Stupp: J Biomed Mater Res A, 84, (2008) 402.

[27] J. B. Li, H. C. Lin, J. S. C. Jang, C. N. Kuo, and J. C. Huang: Materials Letters, 105, (2013) 140.

[28] A. Evans: Progress in Materials Science, 43, (1998) 171.

[29] M. A. Meyers, P. Y. Chen, A. Y. M. Lin, and Y. Seki, : Progress in Materials Science, 53, (2008) 1.

[30] J. B. Li, H. C. Lin, J. S. C. Jang, C. N. Kuo, and J. C. Huang: Materials Letters, 105, (2013) 140.

[31]L. Chaitow: Journal of Bodywork and Movement Therapies, 7, (2003) 202.

[32] V. K. Goel, B. T. Monroe, L. G. Gilbertson, and P. Brinckmann: Spine (Phila Pa 1976)., 20, (1995), 689

[33] M. F. Ashby, A. G. Evans, N. A. Fleck, L. J. Gibson, J. W. Hutchinson, and H. N. G. Wadley, " Metal Foams: A Design Guide: A Design Guide," ed (Publisher, Elsevier, 2000) pp. 251.

[34] Wang X. h, Li J. s, Hu R, Kou H. c, Zhou L.: Transactions of Nonferrous Metals Society of China, 23, (2013) 2317.

(Received: September 19, 2016, Accepted: February 22, 2017) 